\title{
Technology of repairing brick masonry cladding of multi-layer external walls using helical repair anchors
}

\author{
Artem Davidyuk ${ }^{1, *}$ \\ ${ }^{1}$ Moscow State University of Civil Engineering, Yaroslavskoe shosse, 26, Moscow, 129337, Russia
}

\begin{abstract}
As a result of mass construction of residential multi-storey buildings with non-bearing multi-layer walls and brick masonry cladding, during recent 10 years a number of drawbacks were found in design solutions leading to structural failure already at the initial stage of operation. Relevance of this problem is caused by poor reparability of multi-layer wall structures without removing the external brick cladding. The paper describes engineering solutions developed including authors' efforts for repairing such walls without removing the cladding layers.
\end{abstract}

\section{Introduction}

As a result of examinations of multi-layer external walls in more than 50 residential houses of Moscow, root cause analysis of defects has shown that defects of the cladding brick layer are the most common $[1,2,3,4,5]$. With participation of the authors, structural solutions have been developed for repairing the brick masonry cladding of external walls to ensure their future reliable operation. To address these issues, methods have been suggested that involve special repair flexible helical anchors (fig. 1), which have a number of advantages over threaded studs and reinforcement bars [6].

\section{Materials and methods}

The experience of using helical anchors made of stainless metal is well known in Great Britain where there is extensive experience of operation of multi-layer brick walls, in particular, so-called hollow masonry walls. Such type of anchors reliably secure cladding in the inner layer of a wall (Figure 2) - providing reinforcement of existing cracks or arrangement of vertical expansion joints without dismantling the masonry cladding of walls, which is highly relevant for multi-storey residential houses in the Moscow Region situation [6]. It should be noted that these solutions allow a 2-fold reduction of costs of repairing brick masonry cladding compared to conventional solutions that require cladding to be fully re-laid.

\footnotetext{
*Corresponding author: 7707061@mail.ru
} 


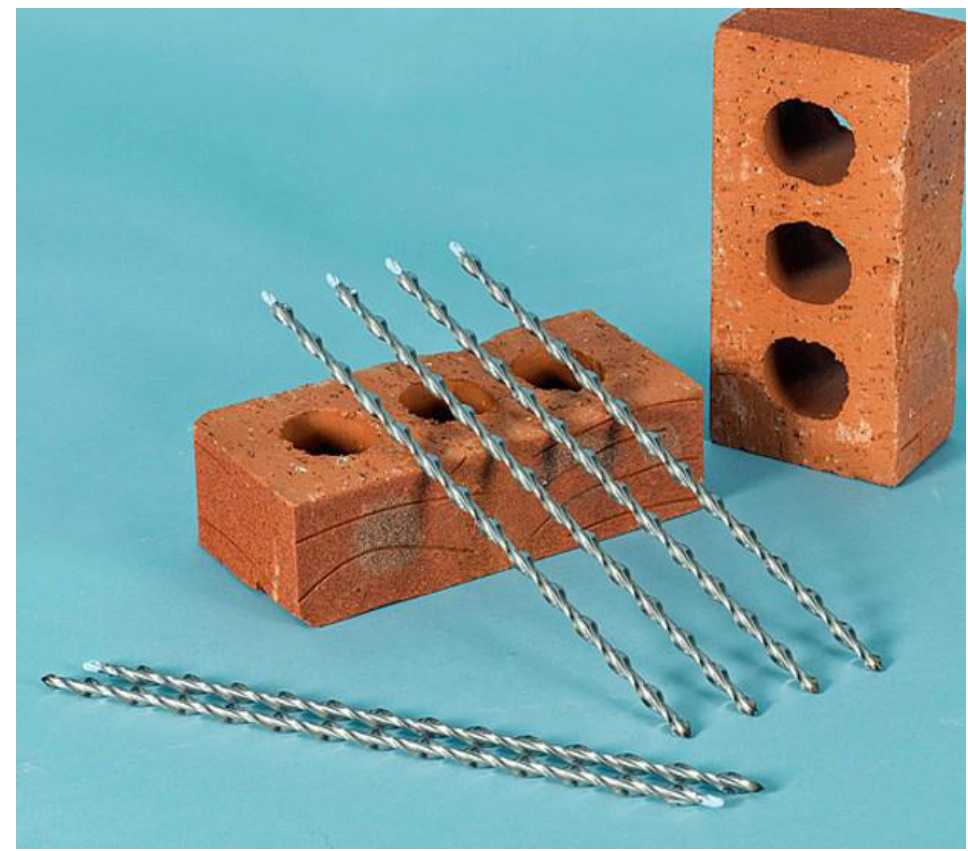

Fig. 1. Flexible repair helical anchors.

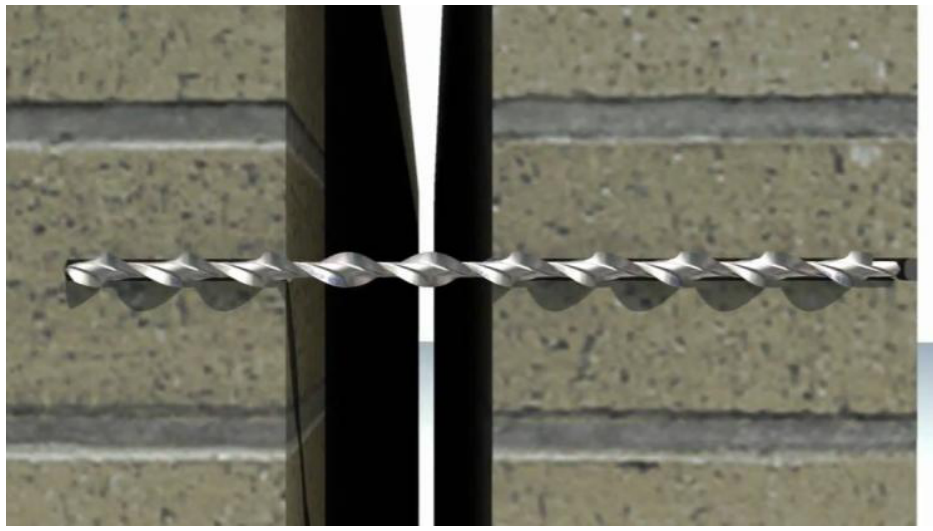

Fig. 2. Connection of brick masonry layers of a wall using flexible repair helical anchors.

Helical repair flexible anchors are fabricated from round stainless wire rolled to form a cross-shaped profile with flat ribs drawn from the center. As a result, the anchor shape allows easy and fast installation by means of impact effect using a hammer or perforator. A repair anchor is secured thanks to self-generated mechanical lock between the spiral and helicoid hole produced in course of installation in the base material (light and cell concretes, ceramic materials, timber). Anchor installation in the base material does not result in stresses or thrust (there are no stress concentrators), so installation may be carried out close to the structure edge. Anchor spacing and depth of fixation in the base is determined by calculation and on the basis of on-site verification tests of anchor fixation in the base material [7].

One of the most valuable advantages is that after repair jobs, the building appearance is almost free of any traces of repair because the braces are installed flush into the base 
material (bricks, concrete, mortar joint), and the point of installation is trimmed by mastic compounds with pigment additives selected to match the façade color.

The presented solutions are standardized and require in-situ testing of connections for strength and deformability and taking into consideration the individual peculiarities of each particular building. Reinforcement may be implemented in a two-layer external wall as well as in a three-layer wall with inner insulation $[8,9]$.

Application of repair helical anchors is recommended in the following cases:

- when brick masonry cladding is reinforced across the wall surface through additional securing in the inner layer;

- when masonry is reinforced in a horizontally and vertically cracked area;

- when cladding fragments are replaced;

- when vertical expansion joints are arranged;

- when masonry is reinforced in the area of lintels.

\section{Results and discussion}

Let us examine the main options of using helical anchors.

Additional securing of brick masonry cladding across the wall field in the base (in the inner layer of a multi-layer façade wall).

At the sections of external walls where the number of flexible ties is insufficient, it is suggested to secure the brick cladding in the inner layer of the outer wall using helical anchors with adhesive compounds $[6,7,10]$. It is recommended to install the anchors staggered at a step of $500 \times 500 \mathrm{~mm}$ on solid wall sections and at a step of $250 \times 250 \mathrm{~mm}$ in the areas of window and door openings.

When an anchor is installed into the inner layer made of cell concrete, installation is performed with a hammer or perforator (fig. 3a) by hammering a tie into the inner layer; when installation is done into a cast-in-situ reinforced concrete, anchor installation must be preceded by drilling a guide hole to the required depth. If the inner layer is airbrick, a tie is fixed using adhesive compounds (Figure 3b) [10].

a)

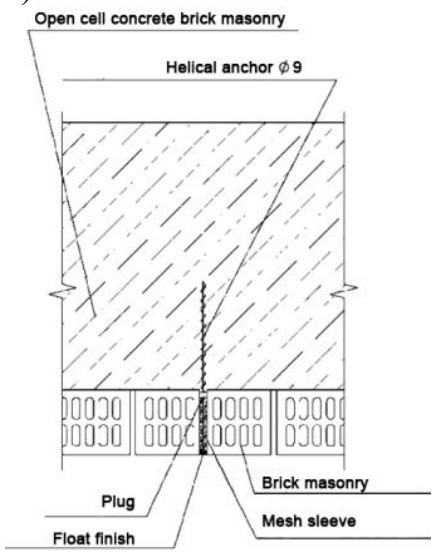

b)

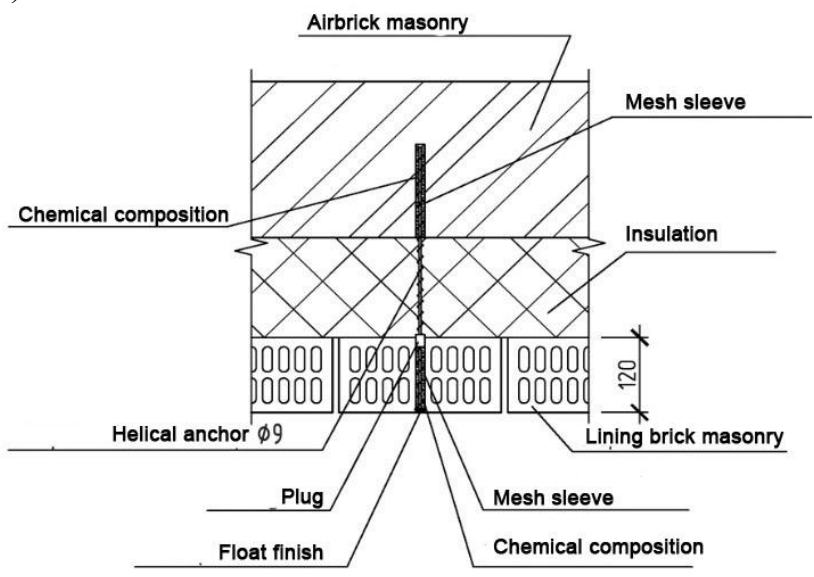

Fig. 3. Schematic drawing of helical anchor installation: a) into cell or light concretes; b) into airbrick masonry.

The anchor is secured in airbrick outer cladding also by adhesive compound filling the hole made earlier required for anchor installation in the inner layer. The hole filled with adhesive compound is float finished flush with the masonry surface. 


\subsection{Reinforcement of brick masonry cladding in a vertical expansion joint arrangement}

In multi-layer outer walls insulated with a layer of efficient insulation or material with low heat conductivity factor, the outer brick cladding layer is practically not heated by indoor air during winter season and, on the contrary, is exposed to high temperatures in summer. Material length and volume variation due to temperature fluctuations result in temperature stresses causing vertical cracking. Vertical and horizontal expansion joints compensate such variations and thus prevent masonry cracking $[1,4,5,11]$.

The distance between vertical expansion joints depends on the multi-layer wall structure and is determined through calculation of temperature and moisture effects. According to calculation findings, for Moscow conditions, the adopted distances between vertical expansion joints in the outer cladding layer of outer walls equal to $10 \mathrm{~m}$.

To arrange vertical expansion joints (Figure 4), $20 \mathrm{~mm}$ wide vertical joints are cut into the brick cladding to the floor height and $120 \mathrm{~mm}$ to the masonry depth; horizontal mortar masonry joints are cut to the depth of $70 \mathrm{~mm}$, to the length of $110 \mathrm{~mm}$ every 4 rows of bricks along the height. Cut horizontal mortar joints are filled with adhesive to the full thickness. Reinforcing bars are inserted at first into mobile plastic tubes. The bar with plastic tube is installed into the prepared earlier horizontal joint at a distance of $50 \mathrm{~mm}$ from the outer surface of brick, so that the tube would be on the right side of the vertical joint. The distance from the free end of the tube to the bar equals to $30-40 \mathrm{~mm}$ to allow for temperature deformations during expansion of cladding section [6].

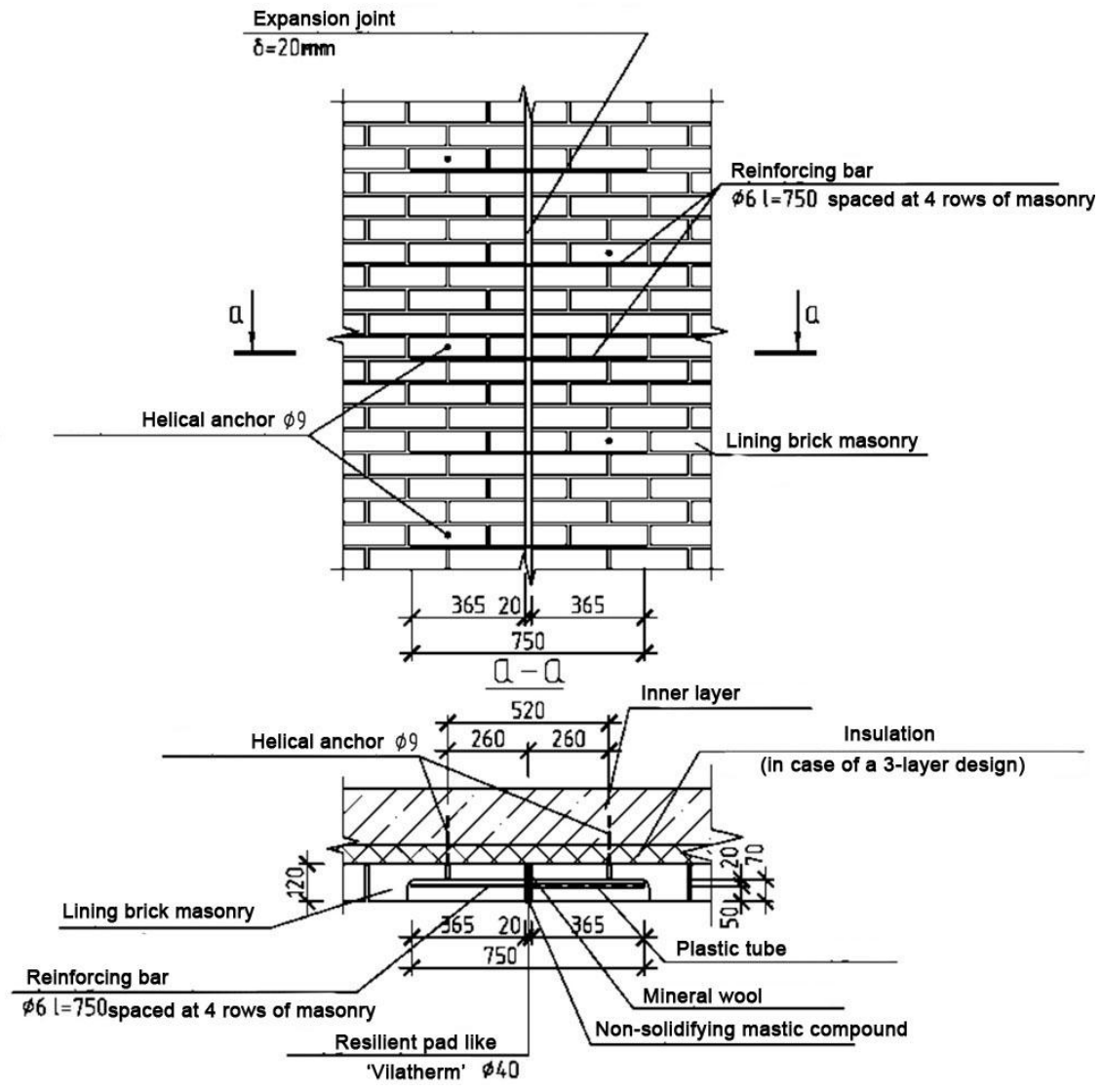

Fig. 4. Schematic drawing of expansion joint arrangement. 
After installation of reinforcing bars, horizontal joints are filled with adhesive compound and float finished by masonry mortar in one plane. To the whole height of a vertical joint, a resilient pad compressed to $2 \backslash 3$ of its diameter is installed and nonsolidifying mastic sealing is applied. Thereafter, point anchors are installed in staggered pattern along the joint height, the anchor length depending on the required depth of embedment in the inner layer of the wall.

\subsection{Reinforcement of cladding masonry in a horizontally and vertically cracked area}

If there are cracks less than $3 \mathrm{~mm}$ in width, it makes sense to reinforce masonry in such areas. Figure 5 shows structural solutions for reinforcing brick masonry areas having cracks of less than $3 \mathrm{~mm}$ in width using reinforcing bars. Horizontal mortar joints of masonry are cut on both sides of a crack to a depth of $70 \mathrm{~mm}$ and a length of $110 \mathrm{~mm}$ every 4 rows of bricks along the height, the crack being in the middle of the mortar joint. Cut horizontal mortar joints are filled with sand-cement mortar to the whole thickness. Reinforcing bars are installed into horizontal joints prepared earlier at a distance of $50 \mathrm{~mm}$ from the outer surface edge of a brick [6].
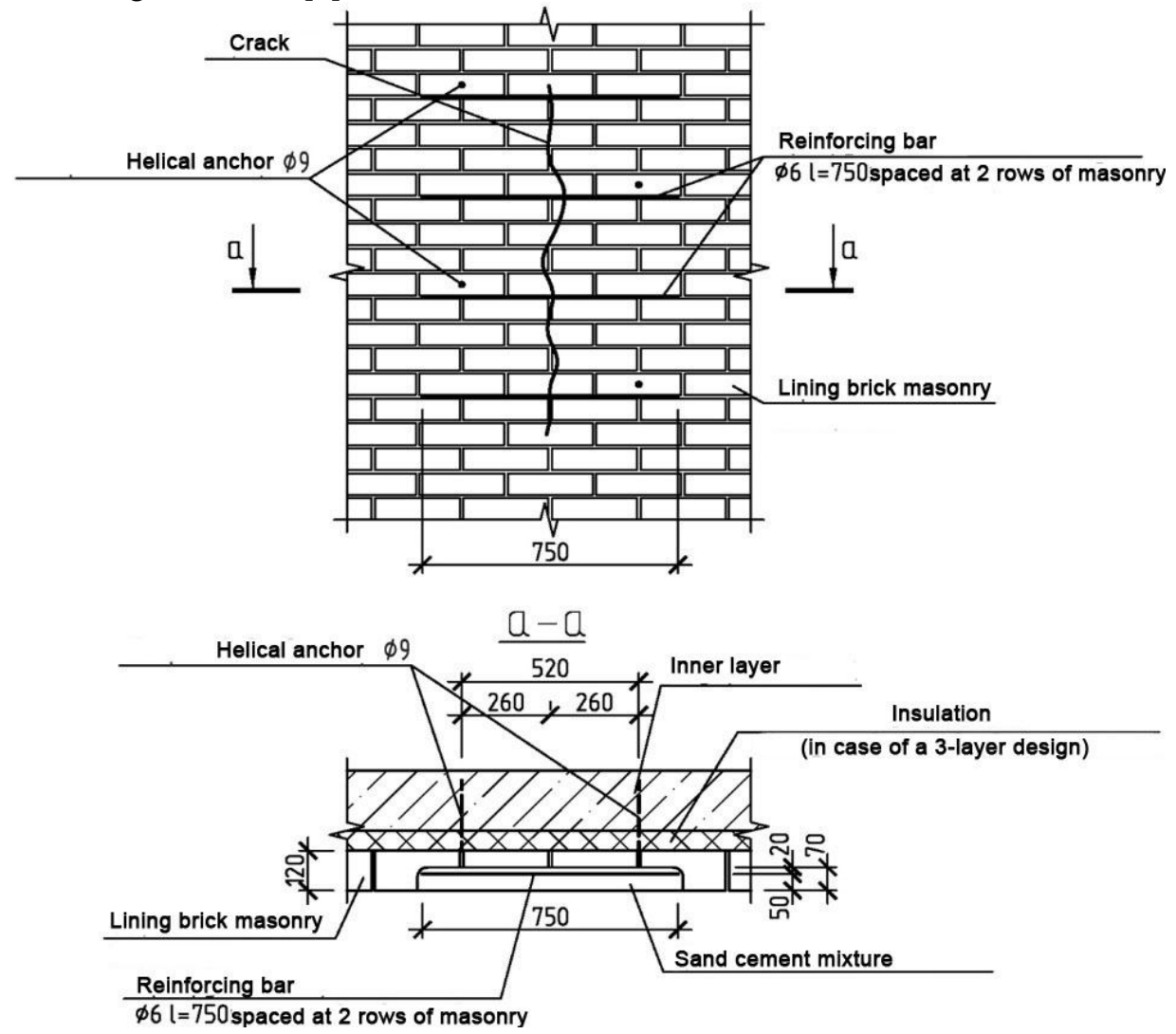

Fig. 5. Schematic drawing of reinforcement of cracks of less than $3 \mathrm{~mm}$ in width.

After installation of reinforcing bars, horizontal joints are filled with sand-cement mortar flush with the wall. Thereafter, $\varnothing 9 \mathrm{~mm}$ point anchors are installed in staggered pattern along the height of a crack, the tie length depending on the depth of embedment in the inner layer of the wall. 
When the cracks in the outer masonry cladding are wider than $3 \mathrm{~mm}$, such area is re-laid (Figure 6). In this case, the new masonry is secured in the inner layer with the help of $\varnothing 9 \mathrm{Mm}$ flexible helical anchors staggered at $500 \times 500 \mathrm{~mm}$ at solid areas and at $250 \times 250 \mathrm{~mm}$ in the areas of window and door openings. For the new brick masonry, a thickened wall brick having hollowness of not more than $15 \%$ is used to prevent brick degradation due to atmospheric air penetration into hollow spaces during autumn and spring. Re-laid masonry areas are reinforced with metal mesh $50 \times 50 \mathrm{~mm}$ every 4 rows along the height $[6,7]$.

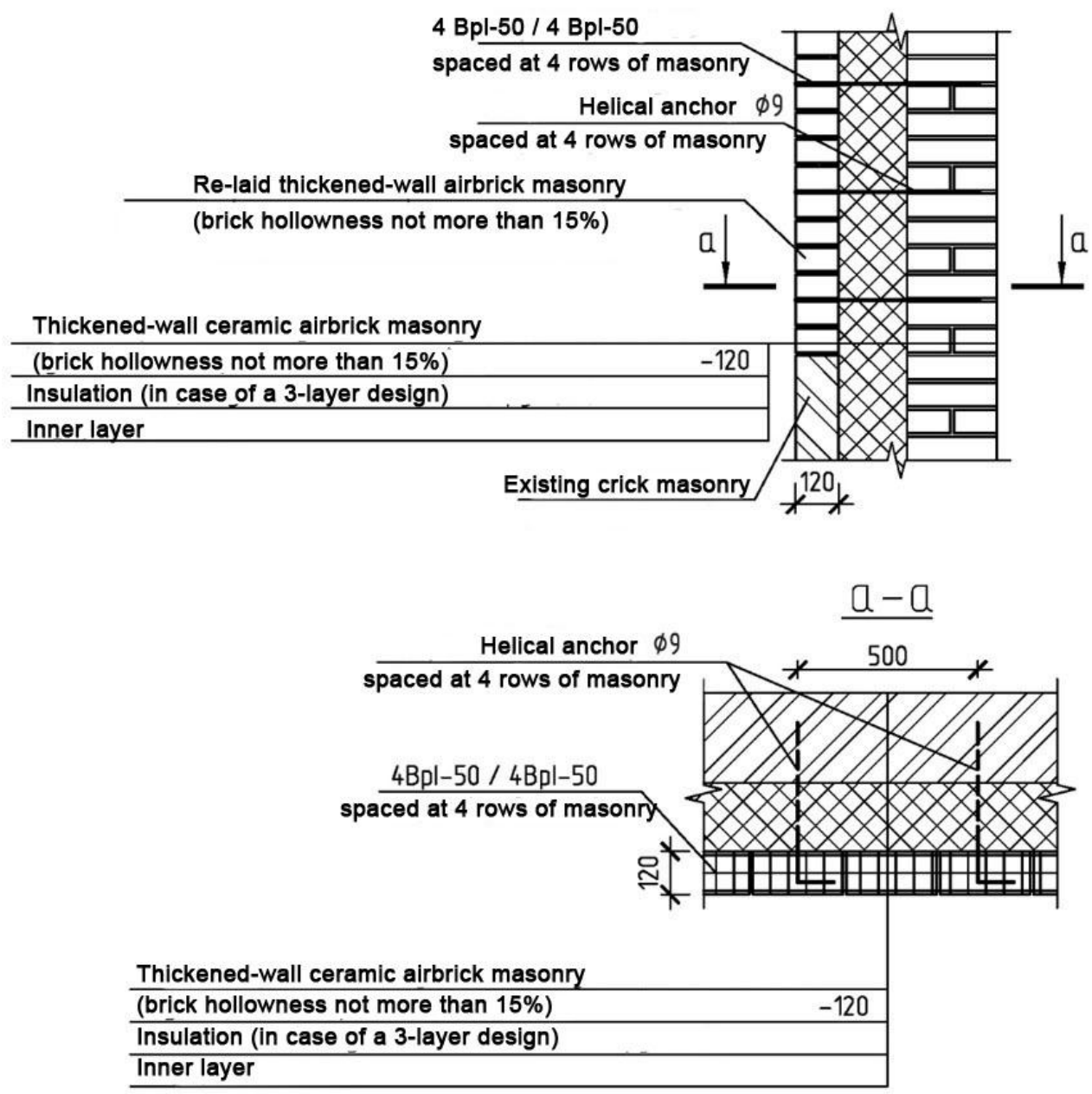

Fig. 6. Schematic drawing of re-laying of outer brick cladding at destroyed sections with cracks wider than $3 \mathrm{~mm}$.

\subsection{In insufficiently insulated areas of outer multi-layer walls}

Insulation can be replaced only by dismantling the existing brick masonry cladding $[1,4$, 11]. In course of installing the insulation between the outer and inner structural layers of façade walls, it is secured onto the inner layer surface with the help of façade disk-shaped dowels staggered at $500 \times 500 \mathrm{~mm}$.

After insulation is installed, the new brick masonry cladding is done according to the schematic drawing described above, using $\varnothing 9 \mathrm{~mm}$ helical anchors. 


\section{Conclusion}

The technological solutions presented in the paper allow high process ability of works and significant reduction of the cost of repair involving rehabilitation of outer multi-layer walls: as much as 2-fold compared to conventional methods. Application of helical repair anchors offers obvious advantage in terms of architecture because it allows retaining the original appearance of a building façade as opposed to the option of replacing the defective brick masonry by ventilated façade.

\section{References}

1. A.S. Gorshkov, M.V. Knatko, P.P. Rymkevich, Stroyprofil 3, 73 (2009)

2. A.V. Granovskiy, Technologii Stroitelstva Journal 4(59), 13-14 (2008)

3. A.A. Davidyuk, Zhilishchnoe Stroitelstvo, 6 (2010)

4. A.M. Ibragimov, Penza Engineering and Construction Institute, 22 (1990)

5. A.M. Ibragimov, S.V. Fedosov, L.Yu. Gnedina, Zhilishchnoe Stroitelstvo 7, 9-12 (2012)

6. E.A. Korol, Yu.A. Kharkin, Theoretic Fundamentals of Construction, 401-406 (2011)

7. E.A. Korol, Yu.A. Kharkin, Stroitelstvo I Reconstruktsia 6, 3-8 (2013)

8. G. Kuznetsova, Technologii Stroitelstva Journal, 1 (2009)

9. V.I. Obozov, A.A. Davidyuk, Bezopasnost Sooruzheniy, 3 (2010)

10. O.I. Ponomarev, M.O. Pavlova, Recommendations and engineering solutions for rehabilitation of hollow ceramic brick cladding in buildings with multi-layer outer walls (CNIISK, Moscow, 2009)

11. A.A. Yavorskiy, S.A. Kiselev, Bulletin of MGSU 12, 78-84 (2012) 